\title{
UCRL-JC-114014
}

PREPRINT

$$
\begin{gathered}
\text { FF VIED } \\
\text { AUG Og } \\
\text { O STI }
\end{gathered}
$$

\section{Precision Machining and Polishing of Scintillating Crystals for Large Calorimeters and Hodoscopes}

\author{
C. R. Wuest \\ B. A. Fuchs
}

This paper was prepared for submittal to the Proceedings of the Fifth Annual 1993 International Industrial

Symposium on the Supercollider (IISSC)

Plenum Press, San Francisco, California

May 6-8, 1993

May 1993

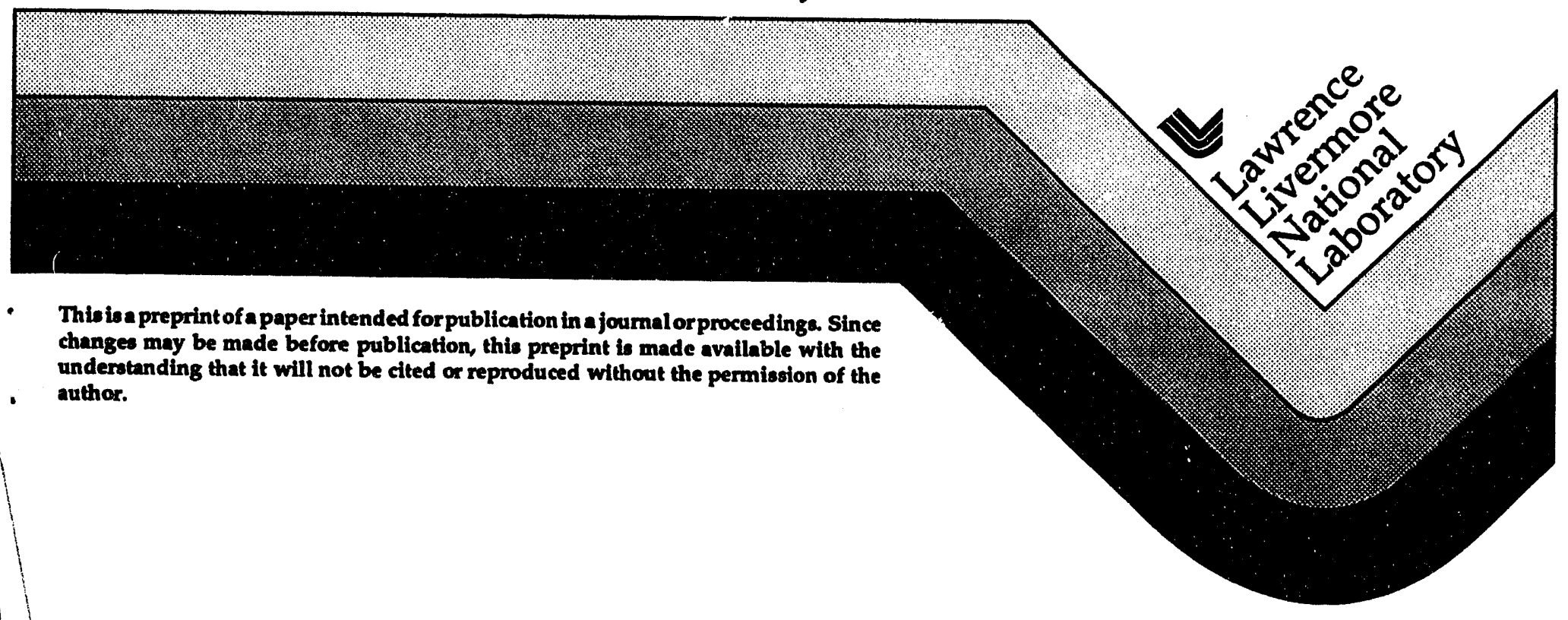

MASTER 


\section{DISCLAIMER}

This document was prepared as an account of work sponsored by an agency of University of California nor any of their employees, makes any warranty, express or implied, or assumes any legal liability or responsibility for the accuracy, completeness, or usefulness of any information, apparatus, product, or process disclosed, or represents that its use would not infinge privately owned rights. Reference herein to any specific commercial product, process, or service by trade name, trademark, manufacturer, or otherwise, does not necessarily consthtute or fimply its endorsement, recommendation, or favoring by the United States Government or the University of California. The views and opinions of authors expressed herein do not necessarily state or reflect those of the United States Government or the University of California, and shall not be used for advertising or product endorsement purposes. 


\title{
PRECISION MACHINING AND POLISHING OF SCINTILLATING CRYSTALS FOR LARGE CALORIMETERS AND HODOSCOPES
}

\author{
Craig R. Wuest, Baruch A. Fuchs \\ Lawrence Livermuie National L aboratory \\ P. O. Box 868 \\ Livermore, CA USA 94551
}

\section{INTRODUCTION}

New machining and polishing techniques have been developed for large barium fluoride scintillating crystals that provide crystalline surfaces without sub-surface damage or deformation as verified by Atomic Force Microscopy (AFM) and Rutherford Back-scattering (RBS) analyses. Surface roughness of about 10-20 angstroms and sub-micton mechanical tolerances have been demonstrated on large crystal samples. Mass production techniques have also been developed for machining and polishing up to five $50 \mathrm{~cm}$ long crystals at one time. We present this technology along with surface studies of barium fluoride crystals polished with this technique. This technology is applicable for a number of new crystal detectors proposed at Colliders including the Barium Fluoride Electromagnetic Calorimeter at SSC, the Crystal Clear Collaboration's cerium fluoride calorimeter at LHC, and the $\mathrm{KTeV}$ and PHENIX scintillating hodoscopes at Fermilab, and RHIC, respectively.

Lawrence Livermore National Laboratory (LLNL) has an active program of study on barium fluoride scintillating crystals for the Barium Fluoride Electromagnetic Calorimeter Collaboration and cerium fluoride and lead fluoride for the Crystal Clear Collaboration. This program has resulted in a number of significant improvements in the mechanical processing, polishing and coating of fluoride crystals. Techniques have been developed using diamond-loaded pitch lapping that can produce 15 angstrom RMS surface finishes over large areas. Also, special polishing fixtures have been designed based on mounting technology developed for the $1.1 \mathrm{~m}$ diameter optics used in LLNL's Nova Laser. These fixtures allow as many as five $25-50 \mathrm{~cm}$ long crystals to be polished and lapped at the same time with tolerances satisfying the stringent requirements of crystal calorimeters. We also discuss results on coating barium fluoride with UV reflective layers of magnesium fluoride and aluminum.

\section{BARIUM FLUORIDE SURFACE PREPARATION AND ANALYSIS}

Surface preparation is critical to the performance of barium fluoride and other fluoride crystals for a number of reasons. First, an improperly prepared (machined, ground, polished, lapped) crystal suffers from induced stresses and deformations in the first few hun- 
dred microns of the surface. These stresses can manifest themselves in the formation of cracks (crazing) over long times, or more quickly when subjected to extremes of heat, radiation, humidity, etc.. Surface stresses can be minimized using well-known polishing and lapping techniques that gently bring the surface to a final finish. These techniques have been developed at LLNL for barium fluoride and also applied to cerium fluoride and lead fluoride. Improper surface preparation can also introduce contaminants into the surface of the crystal. Under certain conditions these contaminants can migrate into the bulk of the crystal and cause extended areas of radiation susceptibility. Because these scintillator materials emit their light typically in the UV, surface finish is especially important for good light transport properties.

A number of surface preparation techniques were explored at LLNL, including ion beam milling, diamond turning, and various polishing/lapping techniques. Ion beam milling provides the best crystalline surface, however, the uniformity of the surface, as well as the surface finish is not very good. In terms of surface finish, diamond-turned surfaces are the best with $6 \AA$ RMS demonstrated. However, RBS analysis of diamond-turned surfaces reveal that they are amorphous. Figure 1 shows an example of diamond-turned barium fluoride with a noticeable crystal grain boundary that exhibits different surface roughnesses. Also shown in Fig. 1 is an example of an improperly polished crystal at similar magnification.

A polishing technique - pitch lapping with diamond abrasives - provides the best combination of surface finish (10-20 A RMS) and surface crystallinity. The technique is applied after more standard polishing techniques and is a simple wheel (lap) prepared with a low melting temperature synthetic pitch. Grooves are formed in the pitch in a pattern to allow cutting fluids, abrasives and ground material to be washed away during the lapping process. The key to the process is a final polish with an abrasive of very uniformly sized diamond, typically $1 / 2 \mu \mathrm{m}$ or $1 / 4 \mu \mathrm{m}$ diameter, imbedded in the pitch. In addition, a nonaqueous cutting fluid such as low viscosity silicon oil, or ethylene glycol is used to uniformly disperse the diamond and to carry away waste material. Water is not a good fluid for diamond because of the tendency of diamond to agglomerate in water. Water is also not desirable because of the slight solubility of fluoride crystals in water. We have verified the high quality of diamond-lapped surfaces using AFM and RBS. This analysis supports our optical measurements and also provides insights into the mechanics of the polishing technique.

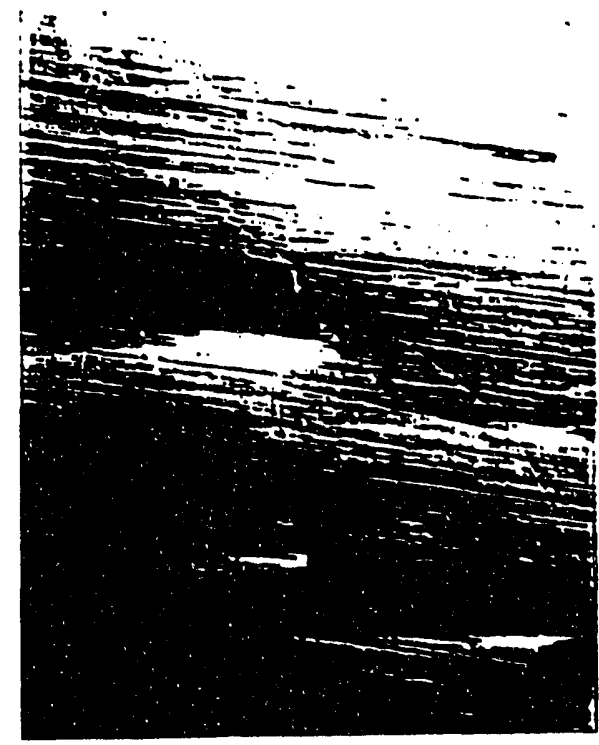

$100 \mu \mathrm{m}$

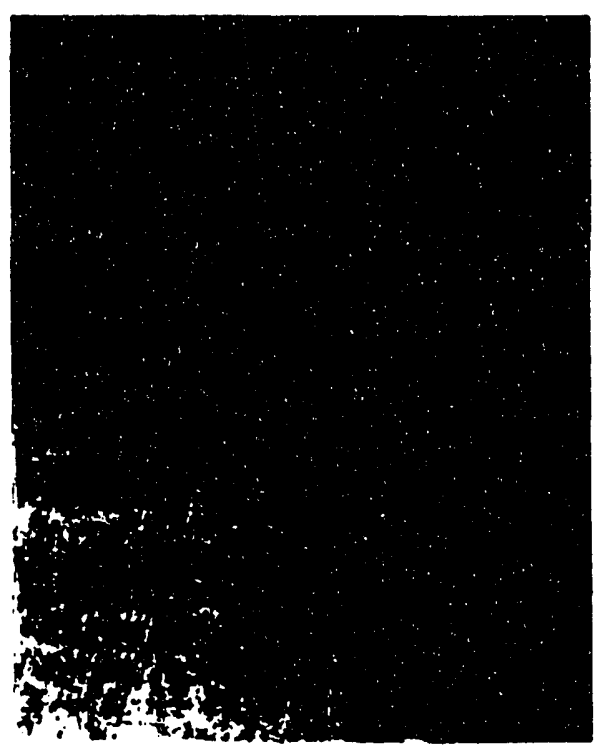

$100 \mu \mathrm{m}$

Figure 1. Photographs (179x) of polished barium fluoride surfaces comparing improper polish techniques (200 A RMS in regions between the large grooves) to diamond turning (6/80 A RMS). 

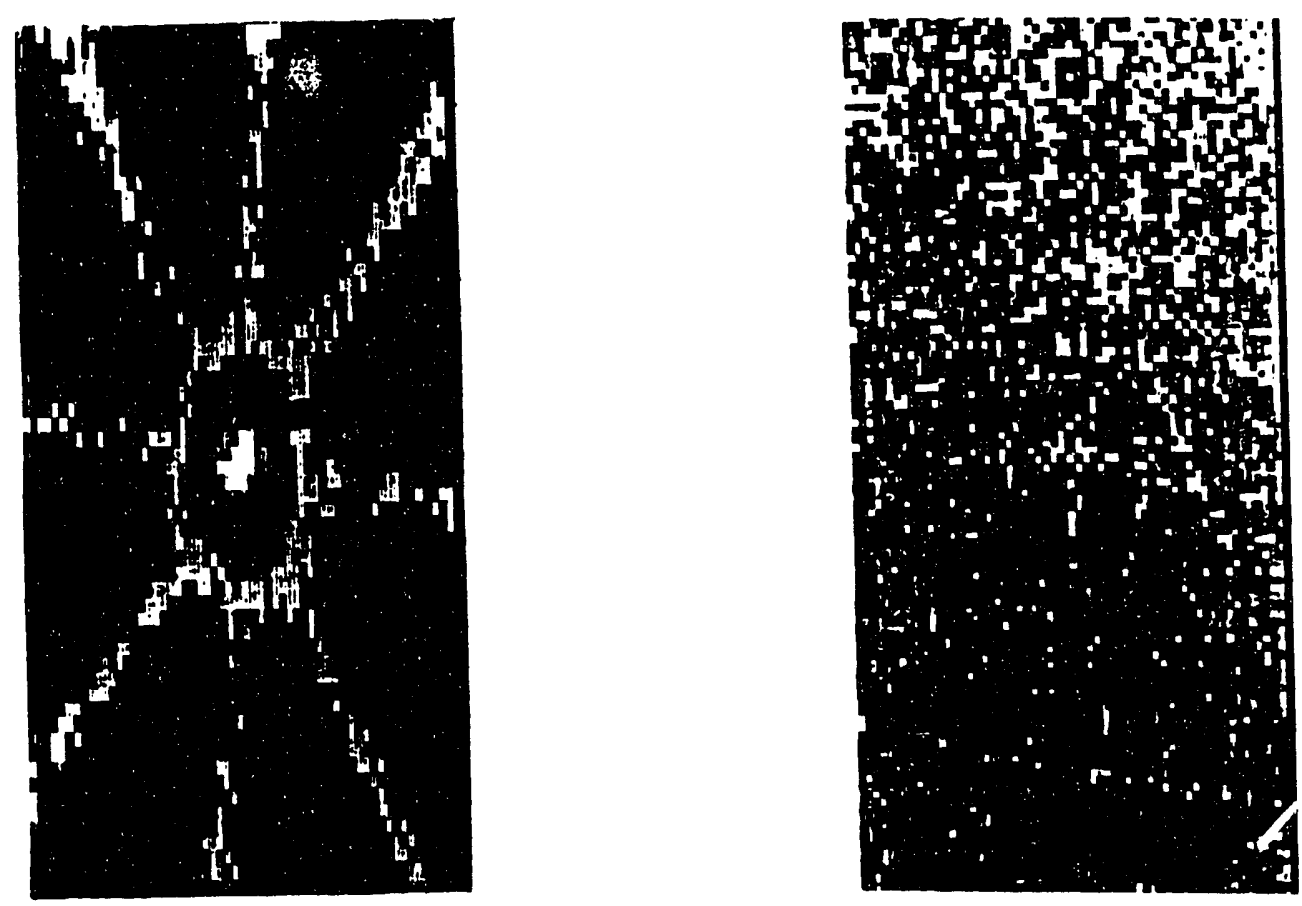

Figure 2. RBS images of polished barium fluoride surfaces showing good (left) and bad (right)crystalline surfaces. The images show the backscatier as a function of $x$ and $y$ tilt angles over a range of $\pm 3^{\circ}$.

Improperly prepared surfaces are easily identified under optical microscopy, and by using other analysis techniques such as RBS. In the case of RBS, helium ions bombard the surface and can channel into the crystal preferentially along the crystal planes. If the surface of the crystal is amorphous, no preferential backscattering is observed. If the crystal surface is crystalline, the crystal lattice is readily identified as peaks in the backscattering number. Figure 2 shows results for crystals prepared at LLNL using improper and proper polishing methods.

LLNL has designed fabricated a set of special polishing fixtures that allow up to 5 crystal halves or pairs (50 $\mathrm{cm}$ length) to be polished at the same time. These fixtures have been used to demonstrate the technique of multiple polishing. It is expected that flatness can be maintained across the full $25 \mathrm{~cm} \times 25 \mathrm{~cm}$ area of grouped crystal halves at the level of a fraction of a wavelengtt of visible light. Also surface finish can be maintained to about $20 \AA$. These fixtures are easily adiapted to existing techniques and machines in use throughout the world. It is anticipated that these techniques would be very desirable for mass production of crystal segments for calorimeters and hodoscopes. Figure 3 is a photograph of the various polishing fixtures.

The polishing techniques developed at LLNL are simple to implement and are essentially extensions of standard polishing techniques already in practice in the US and elsewhere. We feel that these techniques are easily transferred to industry both in the US and overseas. We expect that our techniques can be utilized in production facilities for large scale production of crystal scintillators with little added cost to the overall production of finished crystals. LLNL engineers and physicists have recently visited China to work with the Chinese to develop this capability.

\section{UV REFLECTIVE SURFACE COATINGS R\&D}

High quality surface preparation is also important for insuring the proper application of a reflective coating that exhibits good reflectivity in the $U V$, as well as long term stability. LLNL has experimented with the application of magnesium fluoride and aluminum coatings on barium fluoride. Measurements of front surface reflectance of $500 \AA$ aluminum coatings on barium fluoride have been made alonig with measurements of reflectance through a thin ( $2 \mathrm{~mm}$ ) sample of barium fluoride (back reflectance). Measurements indicate that reflectivity at $220 \mathrm{~nm}$ is about $90 \%$. 


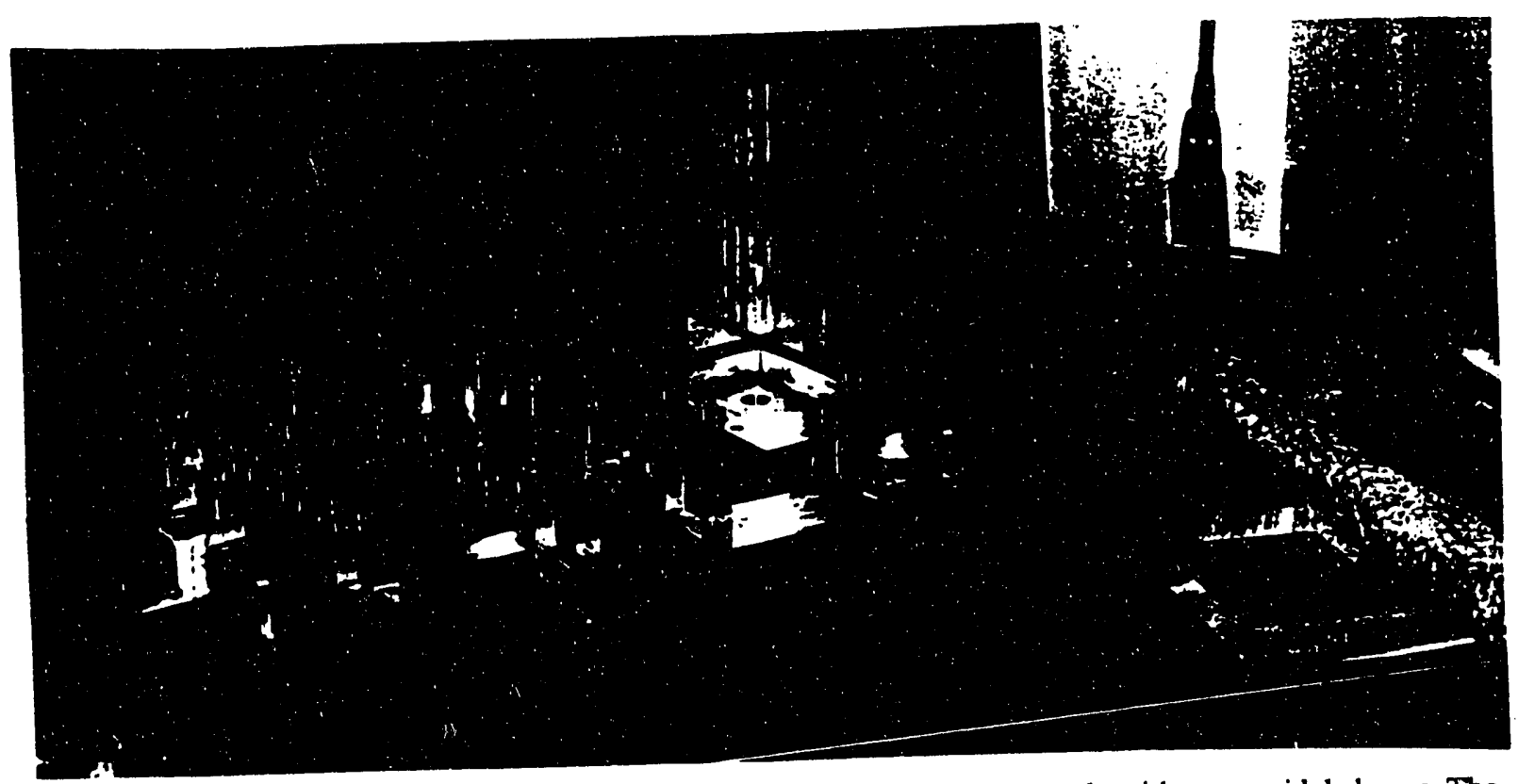

Figure 3. Polishing fixtures developed at LLNL for polishing multiple crystals with trapezoidal shapes. The fixtures allow polishing with a high degree of flatness and excellent surface finish.

Diffuse scattering measurements of the aluminum coating have been made for front surface scattering. It is assumed that this is representative of the diffuse scattering on the back surface into the barium fluoride crystal. Measurements have also been made on magnesium fluoride coatings on barium fluoride to determine the critical angle for total internal reflection.

Additional work is planned to study the long term integrity of coatings. For example, if microscopic pits or pinholes occur, moisture can come into contact with the crystal surface, eventually leading to a degradation of the coating in that region due to chemical reactions that may occur.

LLNL is also helping to provide this data to physicists at Oak Ridge National Laboratory to help model the response of a barium fluoride crystal using a specially written Monte Carlo program. In addition, studies of the response of $50 \mathrm{~cm}$ long crystals to cobalt60 and iron-55 gamma rays and x-rays are being carried out at LLNL, and cosmic ray studies are being made at UC San Diego. These studies are being made for different coating materials and combinations of coatings in an effort to provide uniform collection of scintillation light along the length of the crystal.

\section{CONCLUSIONS}

The polishing and coating techniques described here have been shown to produce surfaces with high quality finishes as well as very good macroscopic tolerances. These techniques are extensions and refinements of basic polishing technology and are easily transferred to industry. Other crystals, such as cerium fluoride are becoming increasingly available for scintillation detectors, and we feel that our experiences described here can be applied for precision mechanical processing and coatings of these materials. We have begun a similar program to study cerium fluoride and we have successfully diamond-turned cerium fluoride to surface finishes of the same quality as for barium fluoride. Also, our coating techniques are directly applicable to the somewhat longer wavelength emission of scintillation light in cerium fluoride.

\section{ACKNOWLEDGEMENTS}

This work was performed under the auspices of the US Department of Energy by the Lawrence Livermore National Laboratory under Contract W-7405-ENG-48. 


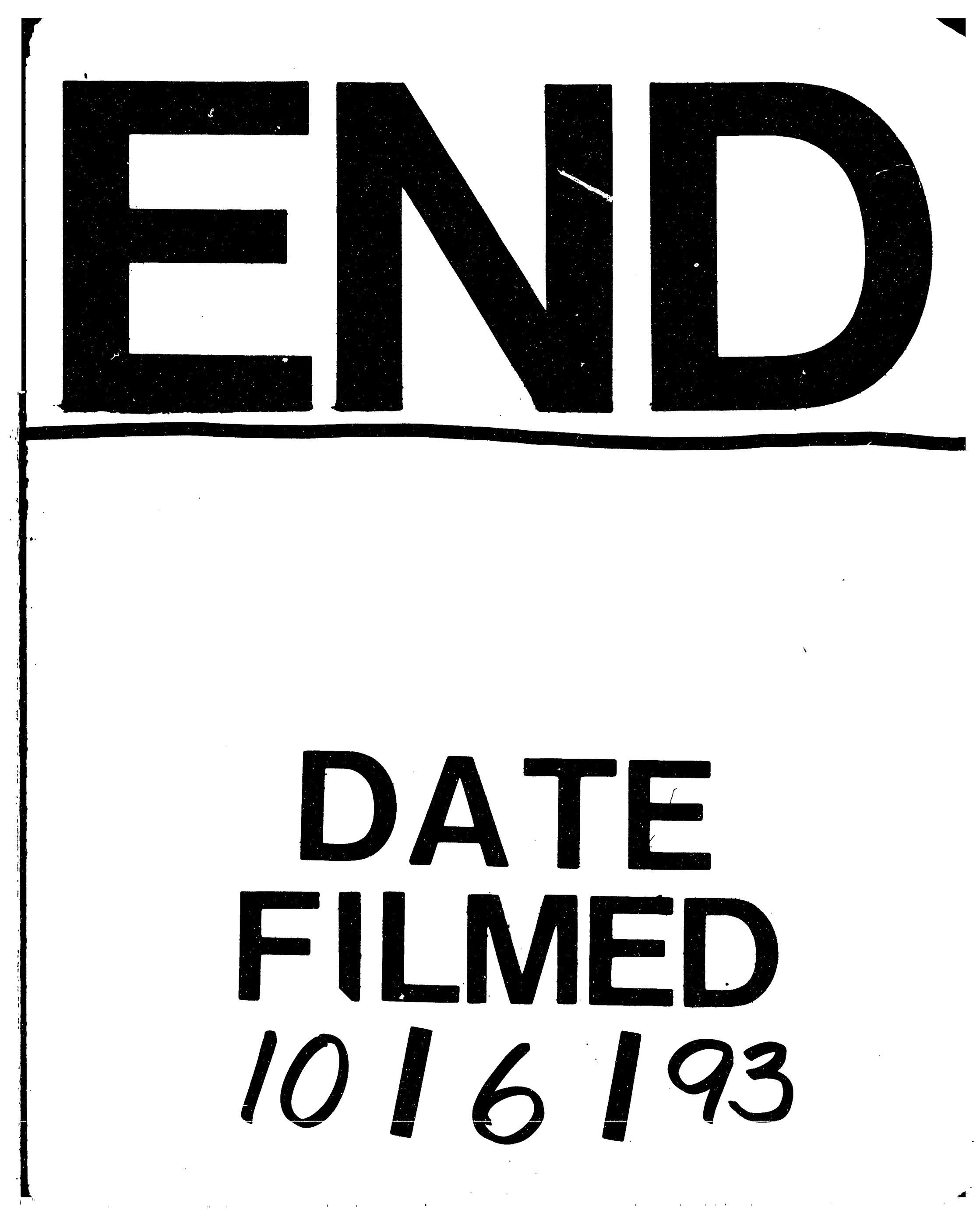




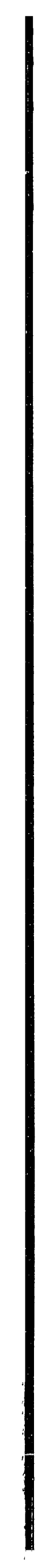

